\title{
A Comprehensive Strategy for Cuban Children and Adolescents
}

\author{
Mercedes Esquivel MD PhD, Gisela Álvarez MD MS, María Elena Izquierdo MD MS, Daisy Martínez MD MS, \\ Vilma Tamayo MD MS
}

\begin{abstract}
The notable rise in survival rates of Cuban children has presented new challenges in the search for continued improvement of their welfare and quality of life. These advances can be achieved only to the extent that preventive care and health promotion are also improved. This article describes the design of a strategy for comprehensive care of children and adolescents based on better quality of well child visits, defining visit components, age-specific activities for each visit, and guidelines for followup based on visit findings. Complementary to the strategy, indicators and standards are identified for systematic evaluation of visit quality, enabling collection of objective and specific information about individual visits and assessment of trends over time, which in turn facilitates further improvements in this strategy over the long term.
\end{abstract}

KEYWORDS Child health services, preventive health services, primary health care, infant mortality, survival, children, adolescents, Cuba

\section{INTRODUCTION}

The Cuban national health system's Maternal-Child Health Program (PAMI, the Spanish acronym) aims to provide comprehensive care to mothers, children and adolescents through prevention, promotion, treatment and rehabilitation services for this population.[1] Among efforts to improve PAMI, a new strategy was designed in 2004, expanding the notion of well child care to encompass well child visits and a range of activities from before birth through age 19 years, to further child and adolescent health and promote optimal growth and development.

The term puericulture, derived from puero (child) and culture (cultivation or care), is attributed to Alfred Caron, who in 1866 published a manual entitled Puericulture or the Science of Raising Healthy Children. Quickly forgotten, the term was later revived by Adolphe Pinard-for many, the driving force and scientific creator of puericulture-who argued for recognition of child care's social importance and the national implications of the principles of puericulture. He defined puericulture as the science whose goal is the research, study, and application of all knowledge related to preservation and improvement of the human species, [2,3] later conceptualizing it as it is currently understood: the set of standards and procedures designed to protect health and promote optimal growth and development of the child, according to his[sic] abilities and genetic potential.[4] Today it is understood that children must also be seen as integral to families and their environment; hence their health care must be analyzed in the context of family and community, and involve integration of biological, psychological, and social factors. $[5,6]$

In Cuba, Dr Eusebio Hernández, a prominent Cuban obstetrician, was the first to write about puericulture, as a result of research he conducted with Pinard in the Baudelocque Clinic in Paris. Pinard authorized him to reproduce their findings in the Physicians' and
Surgeons' Chronicle and other Cuban medical publications of the era. At the end of Cuba's war of independence in 1895, Dr Hernández returned to Havana, where he proposed to Dr Matías Duque, Secretary of Health and Welfare, the creation of a puericulture post in the Research and Studies Section, under the direction of Dr Domingo Ramos, as reported in the Secretariat's official newsletter in 1910.[6]

Before 1959, specialized health care for children reached no more than $10 \%$ of Cuban children and the few existing institutions were providing mainly curative care.[7] Thereafter, pediatric care was available in community-based polyclinics [senior tier of the primary care system, with specialty services-Eds.] provided by both pediatricians and general practitioners. In 1963, Cuba implemented a model of ambulatory health care, in which child health was prioritized and well child visits-primarily for breastfeeding infants—were initiated and universally accessible.[7]

A landmark conference on pediatric practice standards in 1969 had important implications for the evolution of well child care; then Minister of Public Health, Dr Heliodoro Martínez Junco, emphasized that the conference would lead to new initiatives in well child care and research on child growth and development, particularly in the neonatal period and adolescence.[8] The conference capped a process involving thorough review of the relevant literature and intensive discussion among experts in all areas of pediatrics that led directly to publication of a set of standards for pediatric practice, to be used in child health services nationwide. A chapter dedicated to well child care described the optimal clinical setup for organization of well child visits, rostering procedures, and the roles of doctors and nurses within a primary health care framework.[8] In the 1970's, these well child visits were declared the fundamental pillar of child health services in the national health system and were expanded to serve all school-age children.[8]

\section{DEVELOPING A COMPREHENSIVE CARE STRATEGY FOR CHILDREN AND ADOLESCENTS}

In 2012, Cuba's population was $11,163,934$, of which $2,626,614$ or $23.5 \%$ were aged $<20$ years, and 125,093 were $<1$ year (1.1\%).[9] The infant mortality rate that year was 4.6 per 1,000 live births and 5.9 for children aged $<5$ years, [9] ranking Cuba among countries with lowest child mortality.[10] This increase in child survival is striking: in 1970, for every child who died before their first birthday, 25 survived; in 2012, there were 216 survivors for each child who died by age one, a more than eightfold increase over four decades.[9]

This has presented new challenges for continuous improvement in children's wellbeing and quality of life. Such advances are only possible with improvements in health promotion and preventive health care for children. Provision of high-quality well child visits is critical to achieving these goals, given their importance for monitoring and supporting optimal growth and development, as well as for protecting and promoting the health of new genera- 


\section{Policy \& Practice}

tions. Well child visits allow doctors and nurses to monitor physical health and development, assess the quality of parent-child relationships, support optimal family functioning, improve child wellbeing and respond to parental concerns, clarifying points of confusion and correcting misconceptions about child and adolescent care. To ensure such quality, in 2004 the Ministry of Public Health (MINSAP, the Spanish acronym) commissioned a multidisciplinary group, the National Well Child Care Task Force (GNP, the Spanish acronym), under PAMl's leadership.

GNP undertook to improve well child care quality by developing a strategy for family-focused and community-based, ongoing, comprehensive, complete and timely care for children aged 0-19 years. Operating from before birth through adolescence, such care would integrate health, educational, and social aspects of the child's life.[11] Well child care delivers health promotion and disease prevention for children and adolescents, as much for those already living as for those not yet born or conceived, consistent with the pediatric concepts of preconception, antenatal and postnatal well child care. Preconception well child care is still a work in progress, and would involve assuring that at conception, both parents are in optimal condition to foster their child's health and life chances at birth.[12] The current strategy is oriented more toward antenatal and postnatal well child care.

Antenatal well child care is the visit during the last trimester of pregnancy, when the obstetrician and family doctor prepare the future mother for various facets of caring for her soon-to-beborn child. The doctors also discuss with her factors such as the importance of exclusive breastfeeding during the baby's first six months and the value of supplemented breastfeeding until the child's second birthday; transitional diarrhea of the newborn; the importance of a supine sleeping position for the baby; and the importance of well child visits for the child's future development.

Postnatal well child care is provided by the family doctor and nurse [the first level of care, their offices distributed geographically, reporting to a local community polyclinic-Eds.] in collaboration with the polyclinic pediatrician in the catchment area where the child resides. Its implementation is classified by developmental phases:

- newborn (0-28 days)

- infant (1-11 months)

- toddler (1 year)

- preschool (2-4 years)

- school-age (5-9 years)

- adolescent (10-19 years)

Well child care strategic objectives:

1. Promote optimal growth and development in Cuban children aged $0-19$ years

2. Identify, diagnose, and manage any health issues early

3. Prevent or minimize potential future health problems

4. Provide guidance on childrearing and care, and educate children about self care
Design involved the following tasks:

- Define indicators to be assessed during each well child visit

- Define procedures used to assess each indicator selected

- Recommend evaluation criteria and actions to take based on these criteria

- Specify human and material resources needed for the strategy

For each of these tasks, GNP assembled evidence from the substantial Cuban experience in the field[13-15] and from international publications concerning implementation of preventive health care for children and adolescents.[16-19] Based on this, it was determined that-in addition to the importance of a thorough interview regarding occurrences since the previous visit, a careful physical exam, and an accurate assessment of growth and development-it was vital to assess the child's sociocultural and emotional environments. Furthermore, developmental guidelines were needed specific to different age groups, to provide parents and older children with advance notice of normal events in the maturation process that might otherwise become a source of unnecessary concern, or even create future health problems. In addition, the strategy emphasized the need for appropriate advice in response to any and all concerns raised by parents or children during the visits.

Table 1 displays a general overview of well child visit components adopted in the national strategy. Visit frequency was determined by age and biological maturity, and by whether the child was healthy, at risk, had a chronic illness or sequelae, or disabled. Table 2 summarizes information about age-specific activities during visits, including exams to be performed, by medical specialty. All this is documented in Well Child Care-written

Table 1: Overview of the well child care strategy in Cuba

Visit component Interview

\begin{tabular}{|c|c|c|}
\hline & Physical exam & Varies by age \\
\hline $\begin{array}{l}\text { Health status } \\
\text { assessment }\end{array}$ & $\begin{array}{l}\text { Growth and } \\
\text { development } \\
\text { assessment }\end{array}$ & $\begin{array}{l}\text { - } \text { place on growth curve (point and trend) } \\
\text { - } \text { sexual maturity (adolescents) } \\
\text { detection of signs of abnormal neuro-psychomotor } \\
\text { development (at key ages) }\end{array}$ \\
\hline
\end{tabular}

Identifies current and potential problems in family

Assessment of parent-child relationship

Bio-psychosocial diagnosis psychosocial adjustment for:

- prevention of potential problems

- early treatment of family dysfunction

- appropriate referral for serious interaction problems (beyond scope of primary care)

Includes assessment of family and social context, not only individual health and development status

Offer counseling for parents and children about how to

Developmental guides and advice visit

Provides information about

- nutrition

- immunizations

- hygiene

- ways parents can interact with child and encourage psychomotor development

- screening tests for age group

When needed by child, provider specifies medication's name, dosage, frequency and formulation

Schedules next visit, per age and health status 
by the multidisciplinary National Well Child Care Task Forceoffering straightforward explanations that enable providers to comply with strategy guidelines. The document has been updated periodically.[11]

Implementation Once strategy design was complete, a national certificate program was offered, entitled Well Child Care: for a Healthy Childhood and Adolescence, a four-month course attended by selected well child care professionals from all Cuban provinces. Upon completing the course, certificants acted as provincial coordinators, setting up provincial well child care groups and disseminating what they had learned. Additionally, Well Child Care[11] was distributed to all family doctor-andnurse offices (CMF, the Spanish acronym). With all this in place, in 2008 , strategy implementation was initiated nationwide in primary health care.

Well child visits are held in CMFs, the entry level of primary health care, and are complemented by house calls, which provide an opportunity to observe the child, family, and community in their physical, social, and cultural environments. In addition, community polyclinic pediatricians provide followup.

The strategy also includes annual national workshops and postgraduate continuing education courses where new strategy components are proposed and teaching aids developed on child care, all of these with the support and collaboration of UNICEF. Cuba's health web portal, Infomed, includes a site that provides current information for health professionals on practice standards for well child visits in primary health care (http://www.sld .cu/sitios/puericultura).

Evaluation Deming is quoted as saying that you can't improve what you don't monitor, you can't monitor what you don't measure, and you can't measure what you don't define.[20] In that spirit, a guide was developed for evaluation of clinical compliance with strategy activities.[21]

The Well Child Care Quality Evaluation Guide applies Donabedian's principles and recommendations, using his concepts of structure, process, and results, today's leading paradigm for evaluating quality of health services.[22,23] The Guide sets out criteria, indicators, and standards for evaluating the quality of CMF well child visits, and of their analysis at the polyclinic level. These evaluations then are used comparatively to reveal differences in performance among CMFs, polyclinics, municipalities, and the various provinces of the country.

The concept of health care quality has undergone various transformations, each influenced by the social context and by the disciplinary background of the experts defining it. It is unlikely that one framework would be applicable in all locations and to all systems. Donabedian defined quality health care as that which obtains the greatest benefits with the fewest risks for the patient, and the greatest benefits are defined in terms of what is achievable according to existing health care standards and prevailing social values.[24]

Taking this into consideration, the Guide includes nine indicators in a 100-point scoring system for evaluation and monitoring of well child care quality at the CMF and polyclinic levels. The indicators are:
1. Material conditions in the CMF to adequately conduct well child visits. The guide includes a suggested resource list. (Structure indicator, 10 points)

2. Fulfillment of the stipulated frequency of well child visits from antenatal stage until the 19th birthday; if a patient is older than this by the time of evaluation, records are reviewed for only the previous year. (Process indicator, 20 points)

3. Evaluation of visit quality based on chart review: visit components are evaluated using the last recorded appointment. In each CMF assessed, five clinical histories are selected from family medical records, one each from the infant, toddler, preschool, school-age, and adolescent groups. (Process indicator, 30 points)

4. Educational activities in the CMF related to main aspects of well child care. (Process indicator, 5 points)

5. Health problems in the population aged 0-19 years covered by the CMF, with priorities specific to each age group. For example, breastfeeding prevalence in Cuba is currently less than satisfactory and a strategy has been initiated to increase it. Hence, one indicator chosen is proportion of exclusivelybreastfed infants aged $<6$ months and proportion of children aged 6 months-2 years receiving supplemented breastfeeding. (Result indicator, 5 points)

6. Family doctors' and nurses' satisfaction with material conditions, training received in well child care, and interactions with consulting pediatricians. (Result indicator, 5 points)

7. Results of well child care activities evaluation in PAMI meetings held at the polyclinic level. (Process indicator, 10 points)

8. Evaluation of training received by polyclinic and CMF well child care providers. (Process indicator, 10 points)

9. Statistical monitoring of well child care in each polyclinic catchment area. (Process indicator, 5 points)

Indicators 1-6 are evaluated at the CMF level. Evaluation of polyclinic catchment area results is done by averaging scores of CMFs within each area; and evaluation of municipalities and provinces by averaging polyclinic catchment scores. The following categories were established for evaluation of polyclinic catchment areas, municipalities and provinces: excellent (95-100 points); very good (90-94 points); good (80-89 points); average (70-79 points) and poor (<70 points).

Use of the Guide was mandatory following the training provided in the 2010 national workshop. The Guide is now used throughout Cuba, both in annual national monitoring by GNP and in semiannual provincial evaluations.

\section{KEY RESULTS}

Several important developments have taken place since strategy implementation began, although of course they are also influenced by other factors:

- Increased number of well child visits for children aged $>1$ year: from 0.4 visits annually per child aged 1-14 years in 2004, the year the strategy was launched, to 0.7 per child in 2012 (and 0.3 per adolescent aged 15-19 years).[9]

- Well child care has been improved by incorporation of activities such as oral health checkups, genetic screening for selected age groups; active screening for visual, hearing and speech/ language problems; and provision of age-specific developmental guidelines on how to respond to common situations in each life 
Table 2: Well child visit schedule by age group*

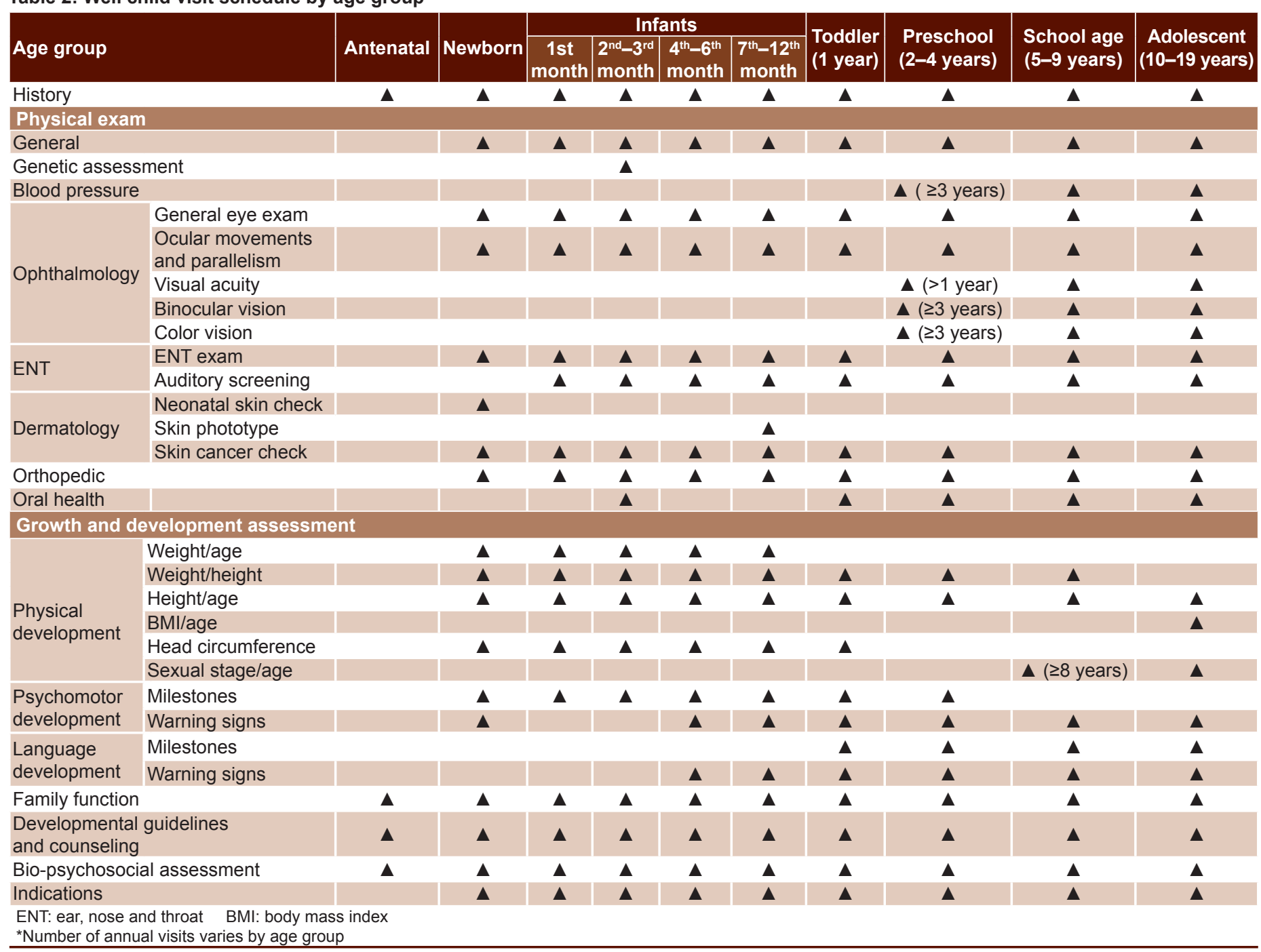

stage. These are additional to existing neonatal screening for congenital endocrine and metabolic pathologies and conditions such as iron-deficiency anemia.

- Prevalence of exclusive breastfeeding up to 6 months of age, although not yet at desirable levels, has noticeably increased, from $26 \%$ in 2006 , to $49 \%$ in 2010.[25]

- Because most prevention and health promotion activities take place in well child care, many of its results are reflected in changes in child and adolescent morbidity and mortality. Unintentional injury prevention provides a good example. Between 2004 and 2012, unintentional injury mortality rates decreased by $27.2 \%$ in children $1-4$ years, $30.4 \%$ in children aged $5-14$ years, and $34.1 \%$ in those aged $0-19$ years (Unintentional injuries were not a leading cause of death in children aged $<1$ year in 2004, and so are not compared).[9]

- Systematic, objective, and specific monitoring of well child care with a standardized instrument has allowed us to identify a gradual trend toward better results in annual national workshops. It has also enabled identification of indicators in greatest need of review; among these are visit frequency for children aged $>1$ year, improvement in implementation of visit activity components, and an increase in educational activities related to well child care.

\section{CHALLENGES AND PROSPECTS}

The main challenge faced is attaining excellence in well child care throughout Cuba, eliminating major differences within and among provinces. The high priority MINSAP accords PAMI is one advantage, as well as the existence of GNP, which sets norms for well child care activities throughout the country. Another strength is the presence of analogous provincial groups that work with the national one in overseeing and monitoring well child care.

Another challenge is the creation and use of an evaluation database based on the Guide, to better monitor performance and detect trends in indicators, identifying those in need of greater attention and permitting interprovincial comparisons. Nationallevel consolidation of this information will facilitate continuous improvement of the current strategy.

The development of a strategy for comprehensive care focused on health promotion, disease prevention, and improvement of care and self care, based on systematic evaluation and improvement of well child visit quality, has had measurable benefits for the health of Cuban children and adolescents. Further benefits can be anticipated to the extent that we continue our push for excellence in well child care throughout Cuba. -1 


\section{REFERENCES}

1. Programa Nacional de Atención Materno Infantil. Havana: Ministry of Public Health (CU); 2013 [cited 2013 Sep 23]. Available from: http://www infomed.sld.cu/servicios/documentos/. Spanish.

2. Cordero D. Reflexiones sobre la pediatría y la puericultura. Rev Soc Bol Ped. 2008;47(2):70-1. Spanish.

3. Rodríguez M. La Puericultura es a la vez Ciencia y Arte. Oviedo (EP): Dirección General de Sanidad (Asturias); 1939. Spanish.

4. Valdés F. Pediatría y Puericultura. In: De la Torre E, Pelayo EJ, editors. Pediatría. Tomo I. Havana: Editorial Ciencias Médicas; 2006. p. 3-6. Spanish.

5. Cruz M. Principios básicos de Pediatría. Introducción. En: Cruz M. Compendio de Pediatría. Barcelona: ESPAXS. Publicaciones Médicas; 1998:13-17. Spanish.

6. Ministry of Public Health (CU). Programa de Trabajo del Médico y Enfermera de la Familia, el Policlínico y el Hospital. Havana: Ministry of Public Health (CU); 1988. p. 70-85. Spanish.

7. Ministry of Public Health Commission (CU). Programa de Desarrollo 2000 Pediatría. Havana: Editorial Ciencias Médicas; 1987. Spanish.

8. Ministry of Public Health (CU). Normas de Pediatría. Havana: Cuban Book Institute; 1971. Spanish.

9. National Statistics and Medical Records Division (CU). Anuario Estadístico de Salud 2012. Havana: Ministry of Public Health (CU); 2013.

10. United Nations Children's Fund. Estado Mundial de la Infancia 2013. New York: United Nations Children's Fund; 2013. Spanish.

11. Grupo Nacional de Puericultura. Consulta de Puericultura. Havana: Ministry of Public Health (CU); 2011.

12. Hernández E. Homicultura. Rev Cubana Salud Púb [Internet]. 2009 [cited 2012 Aug 13];35(3);[about 5 pages]. Available from: http:// bvs.sld.cu/revistas/spu/vol35_3_09/spu10309 .html. Spanish.

13. Esquivel $M$, Arenas $R$, Rubén $M$. Evaluación del crecimiento de niños y adolescentes. Multimedia[CD-ROM]. Havana: Medical Sciences University of Havana; 2010.

14. Jiménez $S$, Pineda $S$, Sánchez R, Rodríguez A, Domínguez Y. Guías alimentarias para niños cubanos hasta 2 años de edad. Documento Técnico para los Equipos de Salud. Havana: Nutrition and Food Hygiene Institute (CU); 2009. Spanish.
15. National Commission for Adolescents Comprehensive Health Care (CU). Programa Nacional de Atención Integral a la Salud de los Adolescentes. Havana: Ministry of Public Health (CU); 2000. Spanish.

16. Duncan P. Bright Futures: Guidelines for Health Supervision of Infants, Children, and Adolescents. $3^{\text {rd }}$ ed. Hagan JF, Shaw JS, editors. Elk Grove Village (US): American Academy of Pediatrics; 2008. $650 \mathrm{p}$

17. Grupos de la Infancia y la Adolescencia del PAPPS. Programa de la infancia y la adolescencia. Aten Primaria. 2012;44(Suppl 1):81-92. Spanish.

18. Massachusetts Health Quality Partners. 2012 Pediatric Routine Preventive Care Recommendations [Internet]. Boston: Massachusetts Health Quality Partners; 2012 [cited 2013 Aug 22]. Available from: http://www.mhqp.org/guidelines /preventivePDF/MHQP PreventiveCareGuide lines_Ped_2012.pdf

19. Asociación Española de Pediatría de Atención Primaria. Programa de Formación. Área de Capacitación Específica en Pediatría de Atención Primaria. Madrid: Exlibris Ediciones; 2010. Spanish.

20. Scherkenbach WW. The Deming Route to Quality and Productivity. 11th ed. Washington DC: CEE Press; 1991.

21. Grupo Nacional de Puericultura. Guía para la evaluación de las consultas de Puericultura [Internet]. Havana: Ministry of Public Health (CU); 2013 [cited 2013 Oct 5]. Available from: http://www.sld.cu/sitios/puericultura/. Spanish.

22. Donabedian A. Evaluating the quality of medical care. Milbank Mem Fund Q. 2005 Dec;83(4):691-729.

23. Donabedian A. Defining and measuring the quality of health care. In: Wenzel R, editor. Assessing quality health care: Perspectives for clinicians. Baltimore: Williams and Wilkins; 1992. p. 41.

24. Donabedian A. Evaluación de la calidad de la atención médica. In: Investigaciones sobre servicios de salud: una antología. Washington, DC: Pan American Health Organization; 1992. p. 382-404. Spanish.

25. National Statistics and Medical Records Division (CU). Cuba: Encuesta de Indicadores Múltiples por Conglomerados 2010/2011, Informe Final. Havana: United Nations Children's Fund; Ministry of Public Health (CU); 2012. Spanish.

\section{THE AUTHORS}

Mercedes Esquivel Lauzurique (Corresponding author: mesqui@infomed.sld.cu), pediatrician with a doctorate in health sciences. Senior researcher, human growth and development department, Julio Trigo López Medical Sciences Faculty, Medical University of Havana (UCMH), Cuba.

Gisela Álvarez Valdés, physician with dual specialties in pediatrics and family medicine and a master's degree in comprehensive child health. GNP coordinator. Assistant professor, Julián Grimau University Polyclinic, Havana, Cuba.

María Elena Izquierdo Izquierdo, pediatrician with a master's degree in comprehensive child health, GNP member. Assistant professor, $\mathrm{UCMH}$, Havana, Cuba.

Daisy Martínez Delgado, physician with dual specialties in pediatrics and family medicine and a master's degree in comprehensive child health. Associate professor, National School of Public Health, Havana, Cuba.

Vilma Tamayo Pérez, pediatrician with a master's degree in comprehensive child health. Adjunct researcher, human growth and development department, Julio Trigo López Medical Sciences Faculty, UCMH, Havana, Cuba.

Submitted: April 22, 2013

Approved for publication: January 10, 2014 Disclosures: None

\section{ERRATUM}

Gorry C. Therapeutic Clowns Bring Joy to Cuban Patients. MEDICC Rev. 2013;15(4):15-17.

Page 15, the photograph caption should read "Reyna (AKA Mantequilla), a professional actor and clown, in the Therapeutic Clowns International workshop at the William Soler Pediatric University Hospital." 